\title{
ИЗМЕНЕНИЕ ПОДХОДОВ К ОЦЕНКЕ ПОТЕНЦИАЛА ЦИФРОВОЙ ТРАНСФОРМАЦИИ ЭКОНОМИК РАЗВИВАЮЩИХСЯ СТРАН
}

\section{CHANGING APPROACHES TO ASSESSING THE POTENTIAL FOR DIGITAL TRANSFORMATION IN THE ECONOMIES OF DEVELOPING COUNTRIES}

\section{E. Karelina}

Summary. This article is devoted to the assessment of approaches to the digital transformation of the economies of developing countries at the current stage of uncertainty in the development of the world economy. The article analyzes the determinants of the participation of developing countries in the international division of labor, as well as the aspects and possibilities of their integration into global value chains in the context of the digital transformation of the world economy. Transformational trends and factors of increased involvement of emerging market countries in international exchange were identified, while their competitive advantages as exporters are significantly changing in the context of the development of the digital economy. Approaches have been developed to strengthen the position of developing countries in the international movement of factors of production in the context of a new wave of scientific and technological progress.

Keywords: digital transformation; scientific and technological progress; developing countries; international division of labor; global value chain.

\author{
Карелина Екатерина Александровна \\ К.э.н., дочент, ФГБОУ ВО «МоскОвский \\ государственный технологический университет \\ «СТАНКИН» \\ opferpriesterin@mail.ru
}

Аннотация. Настоящая статья посвящена оценке подходов к цифровой трансформации экономик развивающихся стран на современном этапе неопределенностей в развитии мировой экономики. Проанализированы детерминанты участия развивающихся стран в международном разделении труда, а также аспекты и возможности их интеграции в глобальные цепочки создания стоимости в условиях цифровой трансформации мировой экономики. Были выявлены трансформационные тенденции и факторы усиленного вовлечения стран с формирующимся рынком в международный обмен, при этом их конкурентные преимущества, как экспортеров, существенно изменяются в условиях развития цифровой экономики. Разработаны подходы к усилению позиций развивающихся стран в международном движении факторов производства в условиях новой волны научно-технического прогресса.

Ключевые слова: цифровая трансформация; научно-технический прогресс; развивающиеся страны; международное разделение труда; глобальная цепочка создания стоимости.
C овременный этап глобализации мировой экономики позволяет констатировать несостоятельность многих подходов к оценке инструментов экономического роста и развития отдельных стран. Так, в специальных исследованиях указывается на то, что парадигма социально-экономического развития и классические модели развития имеют тенденцию к пересмотру [8, с. 104]. В данном контексте отметим, что экономическое и технологическое развитие стран являются взаимосвязанными, а в условиях цифровой трансформации мировой экономики технологический фактор стал ключевой детерминантой оценки конкурентных позиций субъектов мирового хозяйства.

Технологическое развитие субъектов мировой экономики в последние годы описывалось в литературе в контексте анализа национальных инновационных систем (НИС), эффективность формирования и развития которых во многом обеспечила нынешний потенциал цифровой трансформации экономик стран мира. Отмечается, что сформированные в мире НИС достаточно не- однородны, поскольку при их создании использовались разные подходы в части, например, кластеризации, распространения и внедрения инноваций $[12$, с. 149]. Более того, исследователи [11, с. 13] указывают на то, что почти во всех развивающихся странах так и не было создано конкурентоспособных НИС, которые бы способствовали значимому усилению их позиций на высокотехнологичных рынках, а позднее - на рынках цифровых товаров и услуг. Мы отмечаем, что в классической литературе по мировой экономике вопросы цифрового развития экономик зарубежных стран затрагиваются крайне фрагментарно, исключительно в рамках воздействия научно-технического прогресса на развитие национальных экономик и международных экономических отношений [1], [4].

За последнее десятилетие география трансграничной экономической деятельности в мировом хозяйстве изменилась, что обусловлено воздействием цифровой трансформации экономики на международную торговлю, глобальные прямые инвестиции и зарубежную ин- 
вестиционную деятельность. Вместе с тем, объективной проблемой остается наращивание потенциала стран с формирующимся рынком в глобальной добавленной стоимости.

В целом, речь идет о переформатировании места и роли развивающихся стран в новой системе международного разделения труда (МРТ). Современное МРТ формируется преимущественно в рамках участия в глобальных цепочках создания стоимости (ГЦСС), поэтому последовательная и комплексная интеграция развивающихся стран в ГЦСС будет способствовать упрощению их доступа на зарубежные рынки, привлечению прямых зарубежных инвестиций, что, в свою очередь, обеспечит их доступ к новейшим цифровым технологиям. Более того, если страны займут свою нишу в ГЦСС в решении узкоспециализированных задач, это будет вести к росту создаваемой ими добавленной стоимости и национального дохода.

Это особо актуально для малых развивающихся стран с узкими внутренними рынками и с большими барьерами для компаний в части выхода на внешний рынок. К настоящему времени лишь некоторые азиатские страны смогли интегрироваться в ГЦСС, обеспечив технологическое развитие и повышение конкурентоспособности своих отраслей (этот аспект подтверждается современными концепциями [3, с. 9] международного трансферта технологий, на основе которого возможно преодоление отраслевых барьеров). Вместе с тем, актуальной задачей остается встраивание развивающихся стран в высокодоходные сегменты ГЦСС, в частности в постпроизводственную деятельность, что может быть обусловлено высоким потенциалом этих стран по развитию дешевой нематериальной цифровой инфраструктуры, связанной с облачными вычислениями, аналитикой Big Data, «интернетом вещей» и пр.).

Если же рассматривать сегмент проектировки и дизайна продукции, то в этой связи развивающиеся страны испытывают соответствующий дефицит квалифицированных кадров, однако на этой стадии, предшествующей основному производству, цифровые технологии обеспечивают снижение стоимости дизайна и делают его более гибким (наблюдается отказ от высококвалифицированных кадров на данном этапе). Катализатором этого выступают аддитивные технологии, снижающие цикл жизни товаров. Поэтому в условиях цифровой трансформации экономики такие товары могут производиться массово на основе традиционной инфраструктуры и технологий [14], что повышает возможности участия развивающихся стран.

Значительный потенциал положительного воздействия цифровой трансформации на экономику развива- ющихся стран содержится в сфере их участия в международной торговле, которая в последние годы испытывает все новые волны турбулентности, связанные с возросшим межстрановым протекционизмом, ведомым обострением торгового конфликта между США и Китаем. Эта тенденция усугубляется волатильностью курсов валют многих стран, дестабилизацией мировой финансовой системы, ростом оттока капитала из стран с формирующимся рынком, актуализацией так называемой «головоломки производительности». Кроме того, значительным ограничением для развития международной торговли является само распространение цифровых технологий, в условиях которых транснациональные корпорации имеют все меньше стимулов для зарубежного офшоринга своих производств.

Более того, активный экономический рост развивающихся стран в 1990-е годы, казалось бы, формировал условия для преодоления неравенства в уровнях межстранового социально-экономического развития, однако такой конвергенции не произошло, поскольку после кризиса 2008-2009 годов, развивающиеся страны столкнулись с серьезным замедлением экономического роста, а технологический разрыв между странами в условиях цифровизации усилился. Наконец, дешевизна факторов производства развивающихся стран перестала рассматриваться как их основное конкурентное преимущества в международных экономических отношениях. Поэтому, рассматриваемым странам, как отмечает известный исследователь К. Дервиш [13], необходимо специальное регулирование и эффективное внедрение цифровых технологий, чтобы было возможно преодолеть новые указанные разрывы.

Исторически в послевоенные десятилетия наблюдалась значительная интернационализация экономик развивающихся стран за счет существенного усиления их участия в международном обмене как экспортеров, обеспечивающих около двух третей взаимной внутриотраслевой торговли развитых стран. В результате, структура международной торговли стала асимметричной и несбалансированной (что, вероятно, стало ключевой детерминантой усиления неравенства между разными группами стран), а озабоченность по поводу невозможности развивающихся стран извлечь выгоды от участия в обмене возросла. В этой связи актуализировались вопросы эффективности многосторонней торговой политики, однако успехи развития новых индустриальных стран, как экспортно-ориентированных экономик, немного снизили актуальность этих вопросов.

Вместе с тем, к 1990-м годам влияние научно-технического прогресса на развитие мировой торговли расширилось, упростив процессы фрагментации международного производства в рамках ГЦСС и акселерировав 
их участие в международной торговле азиатских стран, главным образом, Китая. Однако, это сопровождалось ростом взаимной торговли развивающихся стран, которая развивалась, с одной стороны, на базе дальнейшей консервации некоторых стран в качестве экспортеров сырья, а с другой - на фоне усиления гиперспециализации таких стран, как Китай. В этой связи, мы бы хотели обратить внимание читателя, на то, что цифровая трансформация мировой экономики не является всеохватной в условиях такой атрофированной и несбалансированной специализации, которая порождает неравенство даже в группе развивающихся стран, с точки зрения их участия в ГЦСС.

Таким образом, гиперглобализация, упоминаемая в современной литературе [6, с. 30-31], привела к тому, что некоторые развивающиеся страны сократили свой разрыв даже с развитыми странами, реализовав потенциал своих технологий для обеспечения диверсификации и модернизации экономики и обеспечив свои прочные позиции в качестве экспортеров продукции обрабатывающей промышленности. Это стало особенно характерным для стран Азии, на которые к середине 2010-х годов уже приходилось до 90\% экспорта промышленных товаров стран с формирующимся рынком $[15$, c. 45].

Мы подробно обращаемся к аспектам участия развивающихся стран в международной торговле в связи с тем, что теоретически, за счет гиперглобализации, развивающиеся страны должны были обеспечить себе узкоспециализированные ниши в ГЦСС, и интеграция этих стран в мировую экономику будет проходить быстрее, чем ранее. На самом же деле оказалось, что в условиях гиперглобализации следствием развития международной торговли является поляризация доходов и неравномерное их распределение не только между развитыми и развивающимися странами, но и внутри последних.

В целом, несмотря на стабилизацию темпов роста международного обмена и усиления участия в нем развивающихся стран, влияние цифровой трансформации, проявляющееся в распространении глобальных цифровых платформ, еще больше упрощает и снижает стоимость трансграничных взаимодействий. Основным конкурентным преимуществом глобальных цифровых платформ являются, по мнению исследователей, отлаженные внутренние взаимосвязи, а также применение концепции совместного использования, в основе которой лежит доступ к благу, а не владение им, что делает использование активов более эффективным [9, с. 61]. Для развивающихся стран важным инструментом является вовлечение в глобальные платформы электронной коммерции, чтобы обеспечивать большую интеграцию потребителей и производителей. Однако, развивающие- ся страны должны также обеспечивать защиту собственных платформ, что возможно на основе механизмов государственно-частных платформ.

В частности, существенный потенциал для развивающихся стран содержится в развитии малых компаний (цифровых, или технологических стартапов), интернационализация которых начинается с их зарождения. Учитывая несомненные выгоды от участия разных стран в глобальных цепочках создания стоимости, которые широко отражены в современной специализированной литературе [10, с. 37], для развивающихся стран политика по распространению и внедрению таких стартапов должна стать определяющей в условиях дальнейшей цифровой трансформации мировой экономики. Такой подход позволит усилить международный трансферт технологий и обеспечить принципиально новую стратегию догоняющего развития для развивающихся стран.

Необходимо также принимать во внимание изменение архитектуры ГЦСС под влиянием автоматизации, «интернета вещей», искусственного интеллекта и глобальных цифровых платформ, которые способствуют усилению международной торговли услугами, которые, казалось бы, благоприятны лишь для развитых стран, как глобальных и основных инноваторов. Однако развивающиеся страны здесь также могут встраиваться в ГЦСС в качестве экспортеров услуг с невысокой добавленной стоимостью. Вместе с тем, в контексте цифровизации ГЦСС следует учитывать, что системы защиты интеллектуальной собственности в развивающихся странах еще достаточно слабы, поэтому офшоринг технологий ведущими транснациональными корпорациями в менее развитые страны пока является сомнительной стратегией.

Развитие цифровых технологий ставит под сомнение модель индустриализации развивающихся стран, основанной на трудоемком экспорте, который параллельно с развитием научно-технического прогресса обеспечил снижение торговых издержек, ускорение международного обмена и усиление специализации стран на производстве новых товаров/услуг [5, с. 7]. В итоге, многие развивающиеся страны перешли от трудоемкого экспорта к освоению ниш новых товаров, что было отчасти обусловлено развитием процессов автоматизации производства, а отчасти - распространением новых цифровых технологий. Пока же выгоды развивающихся стран от их участия в международной цифровой торговле не оценены и не являются очевидными, поскольку в этой группе стран есть существенные проблемы. Например, в части развития цифровой инфраструктуры, цифровых навыков и компетенций, цифрового предпринимательства.

Для экономик развивающихся стран цифровая трансформация экономики, безусловно, является дорогосто- 
ящей, поэтому им необходимо усилить так называемый «абсорбционный потенциал» [2, с. 82] в части усиления своих организационных и институциональных возможностей для ускорения разработки новых технологий и их последующего международного трансферта. Превентивный характер политики по цифровизации экономики, вероятно, является эффективным, однако он должен быть неразрывно связан с цифровизацией потребления, которое должно становится более кастомизированным. В свою очередь, грамотным подходом является производство развивающимися странами реверсных инноваций, производимых зарубежными подразделениями ТНК, а затем используемых на рынке страны материнской компании. Производство таких инноваций может происходить в рамках стратегии интернационализации упомянутых нами цифровых стартапов.

В условиях очевидного монопольного доминирования глобальных цифровых платформ развивающиеся страны практически не предпринимают попыток по обеспечению их неконкурентными практиками, хотя соответствующие инструменты активно используются развитыми странами. Так, многие правительства используют меры по локализации, которые в условиях цифровой экономики означают ограничение расположения вычислительных средств/серверов пределами национальных границ. Такой подход способствует росту прямых иностранных инвестиций зарубежных компаний в цифровую инфраструктуру развивающихся стран, способствует преодолению зависимости от инфраструктуры развитых стран и в целом позволяет защищать зарождающие цифровые отрасли. Также развивающиеся страны должны наращивать собственное производство цифровых услуг, поскольку в настоящее время передача контента идет в основном электронными способами [7, с. 77]. Данное направление может стать ключевым источником перехода от чистого импорта цифровой продукции/услуг к их экспорту. Во многом потенциал роста цифрового экспорта может быть реализован за счет масштабных государственных программ профессионального обучения и поддержки развития цифровой инфраструктуры.

\section{ЛИТЕРАТУРА}

1. Введение в курс мировой экономики (экономическая география зарубежных стран): практикум. Учебное пособие. М.: Кнорус, 2011. 313 с. ISBN: 978-5406-00561-3.

2. Кириллов В.Н., Смирнов Е.Н. Траектория устойчивого роста или очередная разбалансировка механизмов мировой экономики // Вестник МГИм0-Университета. 2019. № 12(5). С. 64-90.

3. Лукьянов С.А. Барьеры входа на рынок и способы их преодоления в условиях глобализации мировой экономики: автореф. дисс. ... докт. экон. наук, 08.00.14 / Лукьянов Сергей Александрович. СПб: Санкт-Петербургский государственный университет, 2008. 45 с.

4. Мировая экономика и международный бизнес: учебник / под ред. В.В. Полякова, Р.К. Щенина. М.: Кнорус, 2009.681 c. ISBN: 978-5-390-00437-1.

5. Мировые рынки товаров и услуг в современных условиях: теоретические аспекты и практика функционирования. Научная монография. М.: Эдитус, 2018. 340 c. ISBN: 978-5-00058-960-1.

6. Смирнов Е.Н. Детерминанты развития международной торговли в условиях гиперглобализации и цифровизации // Российский внешнеэкономический вестник. 2019. № 5. С. 26-40.

7. Смирнов Е.Н. Международное экономическое сотрудничество для преодоления цифрового неравенства // Торговая политика. 2019 . № 2 (18). С. $72-80$. С. 77.

8. Смирнов Е.Н. Противоречия глобального экономического роста, или еще раз об эффективности моделей социально-экономического развития // ЭКО. 2015. № 4 (490). С. 93-104.

9. Смирнов Е.Н., Лукьянов С.А. (2020). Императивы управления глобальными цифровыми платформами // Управленец. T. 11, № 4. C. 59-69. D0І: 10.29141/2218-5003-2020-11-4-5.

10. Смирнов Е.Н., Лукьянов С.А. Оценка трансформирующего воздействия глобальных цепочек создания стоимости на международную торговлю // Управленец. 2019. T. 10. № 3. С. 36-46. DOI: 10.29141/2218-5003-2019-10-3-4.

11. Цифровая трансформация мировой экономики: торговля, производство, рынки. Монография. М.: Мир науки, 2019.95 с.

12. Экономика Европейского союза: инновационный аспект развития. Научная монография. Saarbrucken: LAP LAMBERT Academic Publishing, 2013. 163 c. ISBN: 978-3-659-49258-7.

13. Dervis, K. (2018). A Fragmented Multilateralism? The Brookings Institution, Sept. 11. URL: https://www.brookings.edu/opinions/a-fragmented-multilateralism/ (дата обращения: 22.02.2021).

14. UNCTAD (2017). The new digital economy and development. Technical Notes on Information and Communications Technology for Development, TN/UNCTAD/ ICT4D/08, No 8, 0ctober, $37 \mathrm{p}$.

15. UNCTAD (2018). Trade and Development Report 2018. United Nation Conference on Trade \& Development, N. Y. \& Geneva.

( К Карелина Екатерина Александровна ( opferpriesterin@mail.ru ).

Журнал «Современная наука: актуальные проблемы теории и практики» 